Titulo do Trabalho

\title{
VIVÊNCIAS COM A NATUREZA ENQUANTO PRATICA DE EDUCAÇÃO AMBIENTAL NA ESCOLA: UM RELATO DE EXPERIÊNCIA
}

Nome do Autor (a) Principal

\section{Cleia da Silva}

Nome (s) do Coautor (a) (s)

Carolina Caldeira de Paula; Fernando Protti Bueno.

Instituição ou Empresa

Universidade Estadual Paulista "Júlio de Mesquita Filho" (UNESP)

Instituição (s) de Fomento

Pró-Reitoria de Graduação (PROGRAD)

E-mail de contato

cleia_silva2012@hotmail.com

\section{RESUMO}

Este relato de experiência retrata o desenvolvimento da proposta das vivências com a natureza inseridas como forma de educação ambiental na escola, atendendo a Política Nacional de Educação Ambiental. A proposta está centrada no uso da metodologia do aprendizado sequencial, desenvolvida por Joseph Cornell, que consiste em realizar atividades ludoeducativas em contato com a natureza, mas, para isso, segue a concepção de fluxo em 04 estágios. As atividades proporcionam meios para que os participantes atinjam condições de perceber a natureza tanto física quanto humana, bem como possam ampliar sua consciência ambiental. Foi desenvolvida com 06 turmas dos ensinos fundamental e médio de uma escola estadual do Distrito de Primavera, Rosana/SP, sendo realizadas em uma trilha da Estação Ecológica do Caiuá/PR. A partir disso, foi possível constatar a significativa pertinência da metodologia em conseguir acalmar a mente e proporcionar uma genuína experiência em contato com a natureza. Ao mesmo tempo, também foi possível verificar a dificuldade instaurada a partir de algumas atitudes e comportamentos dos alunos participantes, sendo possível verificar a necessidade de se reencontrar com a natureza, tanto a física quanto a sua natureza humana.

PALAVRAS-CHAVE: Vivências com a natureza; Aprendizado sequencial; Educação ambiental. 


\section{INTRODUÇÃO}

O relato de experiência apresentado tem por objetivo descrever o processo de execução das vivências com a natureza realizadas junto ao projeto homônimo desenvolvido no ano de 2013 no Programa Núcleo de Ensino da UNESP, campus de Rosana, o qual visa desenvolver ações de intervenção educativa em parceria com as escolas públicas. E, para tanto, elencou-se a Escola Estadual Professora Maria Audenir de Carvalho, localizada no Distrito de Primavera, município de Rosana/SP.

A escolha desta escola se justificou pela proposta e ao mesmo tempo pelo interesse no desenvolvimento coletivo de um projeto que contemplasse a educação ambiental no contexto escolar, conforme previsto na Política Nacional de Educação Ambiental (BRASIL, 1999).

Desse modo, se propôs trabalhar com as vivências com a natureza e com o uso da metodologia do aprendizado sequencial, desenvolvida por Joseph Cornell. Considerada uma metodologia original de educação ambiental, visa facilitar o aprofundamento e a interação que os indivíduos podem ter em contato com a natureza, possibilitando o aprendizado e o desenvolvimento de sentimentos e valores, necessários para uma transformação social (CORNELL, 1997; 2008).

Ao desenvolver o aprendizado seqüencial (traduzido do inglês Flow Learning), Joseph Cornell pensou em estabelecer e proporcionar uma melhor relação dos indivíduos com a natureza, pois ao longo de suas experiências com a natureza percebeu que havia um fluxo a ser trabalhado para que as atividades fossem mais produtivas, assim, concluiu que as pessoas reagiam favoravelmente a uma determinada sequencia, em função desta se harmonizar aos aspectos da natureza humana (CORNELL, 1997, 2008).

Cornell (1997, 2008), então, considerou o aprendizado sequencial como uma simples, porém, poderosa estratégia de ensino, que consiste na escolha de atividades lúdicas adequadas, como dinâmicas e jogos, baseadas em princípios universais de consciência e de educação vivencial, organizadas e direcionadas perante uma sequencia de 04 estágios - despertar do entusiasmo; concentrar a atenção; experiência direta; e compartilhar a inspiração - desenvolvidos de forma sutil, 
gradativa e divertida, com a intenção de criar um fluxo de energia, que vá de um estado de maior agitação para um estado de maior concentração da atenção e envolvimento, sendo que esses estágios fluem de um para o outro de maneira suave e natural, onde os participantes passam pelos diferentes estágios e alcançam as estruturas mentais proporcionadas pelas experiências diretas e profundas com a natureza.

Desse modo, as vivências foram realizadas na área da sede e na Trilha do Cedro da junto a Estação Ecológica do Caiuá (unidade de conservação localizada na divisa entre municípios de Rosana/SP e Diamante do Norte/PR).

\section{OBJETIVOS}

Elencam-se enquanto objetivos: compreender as vivências com a natureza enquanto uma forma de desenvolver educação ambiental na escola; descrever as vivências com a natureza realizadas junto ao grupo escolar participante do projeto homônimo do Programa Núcleo de Ensino da UNESP, campus de Rosana; e apresentar o aprendizado sequencial enquanto uma metodologia para o contato com a natureza e a sensibilização ambiental.

\section{METODOLOGIA}

As vivências foram previamente planejadas e, posteriormente, desenvolvidas na Trilha do Cedro da Estação Ecológica do Caiuá/PR em períodos de duas horas e trinta minutos com cada grupo de alunos, no qual mediante o desenvolvimento de atividades lúdicas (jogos e brincadeiras) baseadas na metodologia do Aprendizado Sequencial e por meio das observações registradas em acervo fotográfico e realizadas a partir das características, dos gestos e das ações empreendidas entre os participantes, foi possível proceder a avaliação e a geração de resultados a cada vivência realizada. Esta avaliação foi mensurada pela quantidade de público 
envolvido, tanto em equipe, quanto em discentes atendidos, bem como pelas atividades desenvolvidas.

\section{RESULTADOS}

As vivências com a natureza foram realizadas entre os meses de novembro e dezembro de 2013, junto aos discentes das turmas ${ }^{1} 6^{\circ} \mathrm{A}$, B e C; $7^{\circ} \mathrm{B}$ e $\mathrm{C}$ do ensino fundamental II; e $1^{\circ} \mathrm{B}$ do ensino médio, totalizando aproximadamente 150 discentes. Em geral, se tratavam de salas que apresentavam características heterogêneas de aprendizado, tendo algum bom comportamento e certo relacionamento interpessoal, contudo, também apresentavam em supremacia uma série de dificuldades (trabalho em grupo, e acatar normas e regras), bem como alguns comportamentos perversos (brincadeiras de duplo sentido e de vigor físico, erotização do corpo e preconceito).

Em relação a realização das vivências com a natureza, por uma questão de estabelecer parâmetros para análise e comparação, se buscou realizar as mesmas atividades $^{2}$ dentre um rol de atividades possíveis (conforme mostram as figuras 1 a 4 ), sendo todas estas atividades pensadas e idealizadas por Cornell (1996; 1997. 2005; 2008) para o desenvolvimento da metodologia do Aprendizado Sequencial.

Cada atividade planejada e executada continha a intenção de despertar diferentes reações nos educandos (conforme a proposta dos estágios de Cornell), para que ao final das mesmas tivessem condições para atingir a compreensão dos princípios que haviam por trás das brincadeiras.

No decorrer do desenvolvimento das vivências com a natureza e suas atividades foi possível observar diferentes reações nos alunos. Por diversas vezes obtivemos boas respostas comportamentais ao longo de cada atividade, onde era possível notar o envolvimento com a atividade e entre si, contudo, as reações não

\footnotetext{
${ }^{1}$ Algumas destas turmas eram denominadas de salas vulneráveis, inclusive incluindo nestes casos, duas turmas de recuperação intensiva (RI).

${ }_{2}^{2} \mathrm{~A}$ execução das atividades até pode seguir um suposto roteiro, contudo, o ideal é que o educador possa sentir ao longo da vivência a necessidade e a pertinência na realização de uma ou outra atividade, de acordo com o estado de cada grupo.,
} 
foram as mesmas em todos os grupos participantes, pois em algumas atividades as os resultados almejados não ocorreram, supostamente por inúmeros motivos.

Em relação a metodologia do aprendizado sequencial, notou-se que por diversas vezes à cada brincadeira os alunos conseguiam alcançar as qualidades abordadas pelos estágios, sendo que ao final da vivência conseguia-se alcançar os resultados esperados.

Em geral, foi possível notar que alguns fatores atuavam de modo a influenciar positiva e negativamente o andamento das atividades e os resultados das atividades. Em alguns casos, os professores que acompanhavam os alunos, muitas das vezes, causavam distração, tirando-lhes a atenção necessária ou mesmo sem perceber reprimiam os alunos, o que atrapalhava o andamento da atividade, causando certa inibição, e, nesse sentido, influenciava negativamente, pois o sentimento de liberdade é algo que contribui para se poder ampliar a consciência.

A interação estabelecida entre os grupos foi considerada um fator positivo, pois quanto mais unida e interativa a turma se mantinha, mais condições as mesmas dispunham para alcançar a estrutura mental proporcionada pela metodologia, pois assim, a participação nas atividades ocorria com maior interesse, havendo momentos de grande euforia, interesse e envolvimento.

Uma das atividades em que se notou que os alunos expressaram grande sensibilidade foi a Encontre a arvore $^{3}$ (Figura 03), onde os alunos passaram a tratar as arvores como seres humanos, como se de fato sentissem um coração pulsar, sendo ainda possível perceber por meio do sentido do tato o toque na arvore, estabelecendo um grande apego e uma verdadeira interação com o meio físico.

Mas, essa sensibilidade e interação, bem como alguns dos resultados esperados a partir do uso da metodologia do aprendizado sequencial, não ocorreram com todos os grupos de alunos. Em alguns casos, a interação já era difícil e conflituosa entre eles. Alguns alunos agiam de maneira agressiva (verbal e por vezes fisicamente, sob forma de brincadeira) o que atrapalhava tanto a execução da atividade quanto o interesse de demais alunos em participar, pois havia receio sobre o que o outro iria falar do colega, e, isso, acabava reprimindo o interesse em participar e

\footnotetext{
${ }^{3}$ Considerada enquanto uma das atividades símbolo da metodologia do aprendizado sequencial.
} 
se envolver, por vergonha de se expor.

O maior medo e desconforto observado em todos os grupos de alunos, sem exceção, era o momento de ser vendado (Figuras 1, 3 e 4), sendo que a grande maioria usava as vendas com certa tranqüilidade, já outros demonstravam uma grande aversão à restrição do sentido da visão e, por vezes, tentavam buscar um meio para retirar ou mesmo continuar observando o que estavam fazendo.

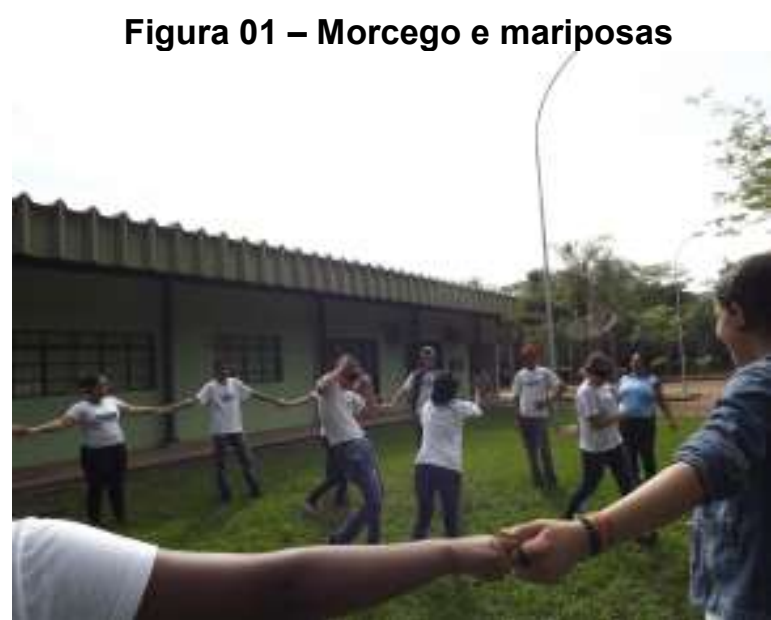

Fonte: acervo próprio

Figura 03 - Encontre a árvore

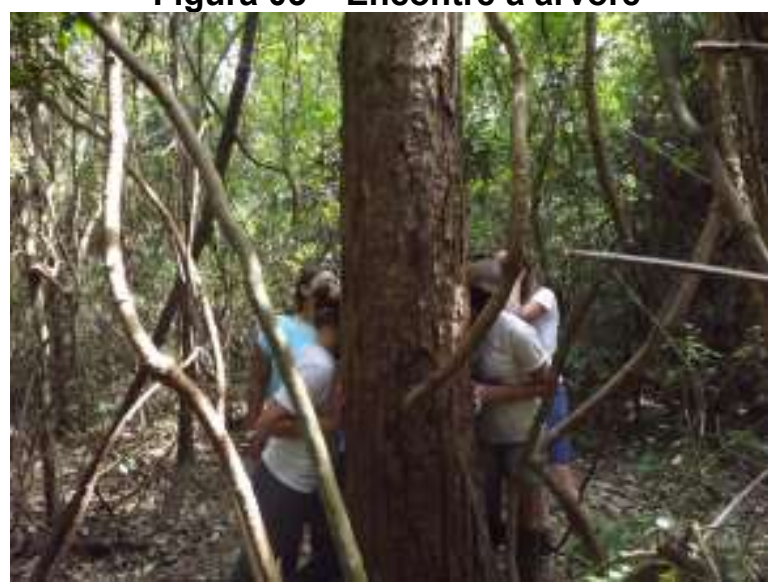

Fonte: acervo próprio
Figura 02 - Trilha de surpresas

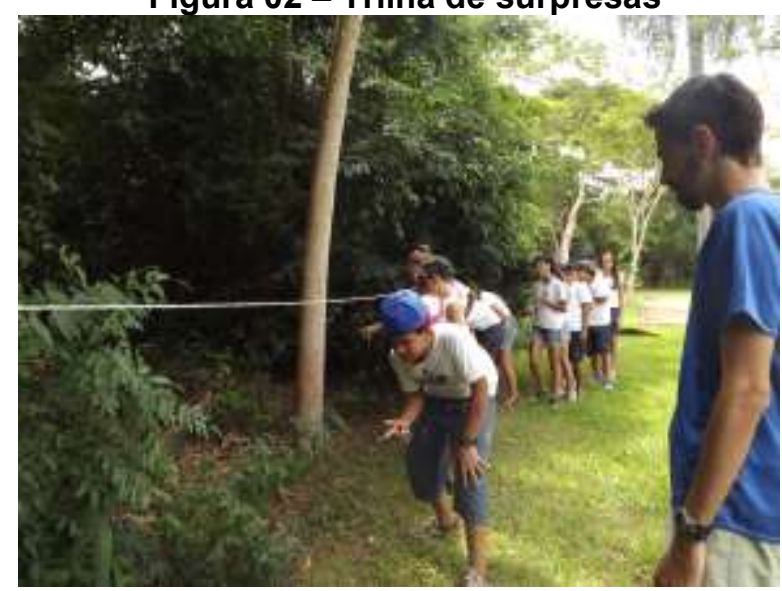

Fonte: acervo próprio

Figura 04 - Passeio da Lagarta

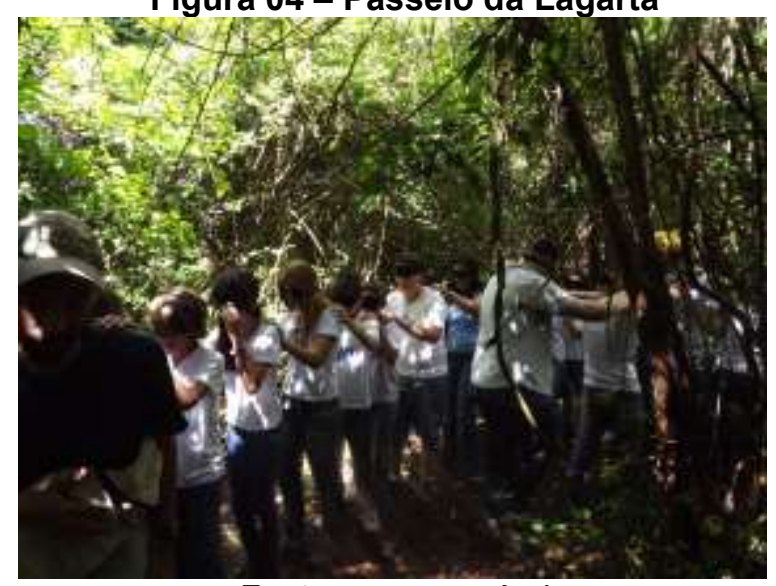

Fonte: acervo próprio

Cada grupo teve uma forma de se relacionar, e, isso, sem duvida alguma, foi um fator que influenciou nos aspectos positivos e negativos ao longo das atividades e nos resultados ao fim da vivência com a natureza. Contudo, apesar da dificuldade de interação de alguns alunos, houve algumas atividades as quais estes interagiram e se entregaram sem perceber, se deixando levar pelos sentimentos aflorados. Sendo 
assim, é possível dizer que ao fim das atividades todos os participantes saíram renovados e integrados com o meio no qual vivenciaram, uns mais que outros.

Ao fim das atividades todos expressaram em gestos e em seus semblantes uma expressão de calmaria e atenção para com o próximo e para com o meio no qual acabarem de vivenciar, e, nesse sentido, foi possível observar a mudança na maneira que se comportavam no inicio e no fim das atividades. No inicio estavam agitados e ansiosos e ao fim, calmos e reflexivos onde puderam contar ou escrever suas experiências, podendo expressar o que sentiram.

\section{CONSIDERAÇÕES FINAIS}

É possível concluir que as atividades ludoeducativas propostas pelo aprendizado sequencial tem o poder de integrar os participantes com a natureza de maneira substancial, uma vez que as atividades buscam por meio de experiências reconectar os mesmos ao meio de modo reflexivo e muito mais intimo do que a educação ambiental puramente verbal e informativa.

Assim, a partir do contato direto com a natureza, os alunos conseguiram expressar seus sentimentos e por meio da experiência vivida e pelos diferentes sentidos trabalhados, bem como sentimentos emanados, puderam tentar reencontrar os valores perdidos e/ou esquecidos.

Desta maneira entende-se que as vivencias com a natureza são uma ferramenta de grande importância na experiência dos alunos, por possibilitar a elevação de sentidos e sentimentos, sendo passível, de ser utilizada como forma de educação ambiental na escola. E, nesse sentido, cabe ressaltar o significativo papel exercido pela metodologia do aprendizado sequencial de Cornell, que por meio de sua proposta auxilia os alunos a se sensibilizar e a ampliar sua consciência.

\section{REFERÊNCIAS}

BRASIL. Decreto-Lei n9.795, de 27 de abril de 1999. Lex: legislação federal. Brasília: DF; 1999. Disponível em: <http://www.mec.gov.br/se/educacaoambiental/pdf/lei979599.pdf> Acesso em: 23 out. 2005. 
CORNELL, Joseph. Brincar e aprender com a natureza: um guia sobre a natureza para pais e professores. São Paulo: Companhia Melhoramentos: Editora SENAC São Paulo, 1996.

A alegria de brincar com a natureza: atividades na natureza para todas as idades. São Paulo: Companhia Melhoramentos: Editora SENAC São Paulo, 1997. Aquariana, 2005.

Vivências com a natureza: guia de atividades para pais e educadores. São Paulo: Aquariana, 2008.

Vivências com a natureza 2: novas atividades para pais e educadores. São Paulo: 